\title{
Treatment of malignant obstruction of the superior vena cava with the self-expanding Wallstent
}

\author{
K W Stock, A L Jacob, M Proske, C T Bolliger, C Rochlitz, W Steinbrich
}

\begin{abstract}
Background - Obstruction of the superior vena cava (SVC) in malignant disease can cause considerable distress to patients. Symptomatic relief can be achieved by the percutaneous implantation of a selfexpanding stent (Wallstent) into the stenosis.

Methods - Fourteen patients with obstruction of the SVC were treated with one to three Wallstent endoprostheses. They suffered from advanced bronchogenic carcinoma $(n=12)$, thyroid carcinoma $(n=$ $1)$, and breast carcinoma $(n=1)$. The indication for stent placement was symptomatic obstruction of the SVC and incurable disease. Stenting was performed for symptom relief, and before, during, and after courses of radiotherapy or chemotherapy as needed.

Results - Twelve patients experienced complete symptomatic relief within two days of stent placement. Two patients did not benefit. Three patients not given anticoagulation developed stent thrombosis between one week and eight months after initial placement, and within one day of endobronchial stent implantation with bronchial laser therapy or balloon dilatation in all three. Patency of the SVC was achieved again by a repeat procedure. Conclusions - Stent placement for obstruction of the SVC gives rapid symptomatic relief. Subsequent endobronchial stent implantation with bronchial laser therapy or balloon dilatation could be a risk for caval stent occlusion. Stent thrombosis remains a problem in patients who are not anticoagulated.

(Thorax 1995;50:1151-1156)
\end{abstract}

Keywords: stent, obstruction, superior vena cava, malignancy.

Stenosis and occlusion of the superior and inferior venae cavae and large veins can be a major problem in patients with malignant disease. ${ }^{1}$ Obstruction is mostly due to compression or infiltration by tumour and may be complicated by secondary thrombosis. Bronchogenic carcinoma is the most common cause of an obstruction of the superior vena cava (SVC). Obstruction can also occur with postirradiation fibrosis or mediastinitis and in the venous outflow tract of arteriovenous dialysis shunts. In earlier reports a large percentage of cases of obstruction of the SVC were due to tuberculous mediastinitis and syphilitic aortic aneurysms. Obstruction of the SVC as a result of malignancy is conventionally treated by radiotherapy and/or chemotherapy. ${ }^{23}$ However, certain patients do not respond or there may be tumour recurrence. In some patients maximum chemotherapy or radiotherapy tolerance may already have been reached. Treatment of severe congestive symptoms with medication other than chemotherapy usually provides minimal relief. Venous stents seem to offer another alternative for the fast relief of symptoms. We placed intravenous stents in patients suffering from incurable malignant disease causing obstruction of the SVC. This approach has been reported using the Gianturco stent, ${ }^{4-13}$ the Wallstent, ${ }^{14-18}$ and the Palmaz stent. ${ }^{19}$ We report on 14 patients treated with the self-expanding Wallstent.

\section{Methods}

PATIENTS

Fourteen patients ( 10 men) of age range 46-75 years (mean 62) were treated with 28 intravenous Wallstents (mean 2.0) (Schneider (Europe AG), Bülach, Switzerland). Stent placement was performed for palliative treatment of incurable malignant compression of the SVC or innominate and subclavian veins (fig 1) with congestive symptoms in all patients. Twelve of the patients had carcinoma of the lung (four with small cell lung carcinoma), one patient had thyroid cancer, and one had breast cancer. The patient with thyroid cancer received an additional stent implantation in the internal jugular vein. The four patients with small cell lung carcinoma had chemotherapy before stenting, and also after venous stenting. Three patients with non-small cell lung carcinoma had had radiotherapy of the mediastinum before stenting and four further patients received radiotherapy after implantation of the venous stent. Two patients received endobronchial brachytherapy as additional radiotherapy. Informed consent was given by all 14 patients.

\section{STENT PROPERTIES}

The Wallstent is non-ferromagnetic and MRI safe. It is constructed with filaments of medical grade stainless steel which are woven in a crisscross tubular pattern. The non-soldered crosspoints of the filaments give the stent flexibility and make it self-expanding. It is mounted on a catheter device which is introduced over a guidewire through an introducer. The stent is 


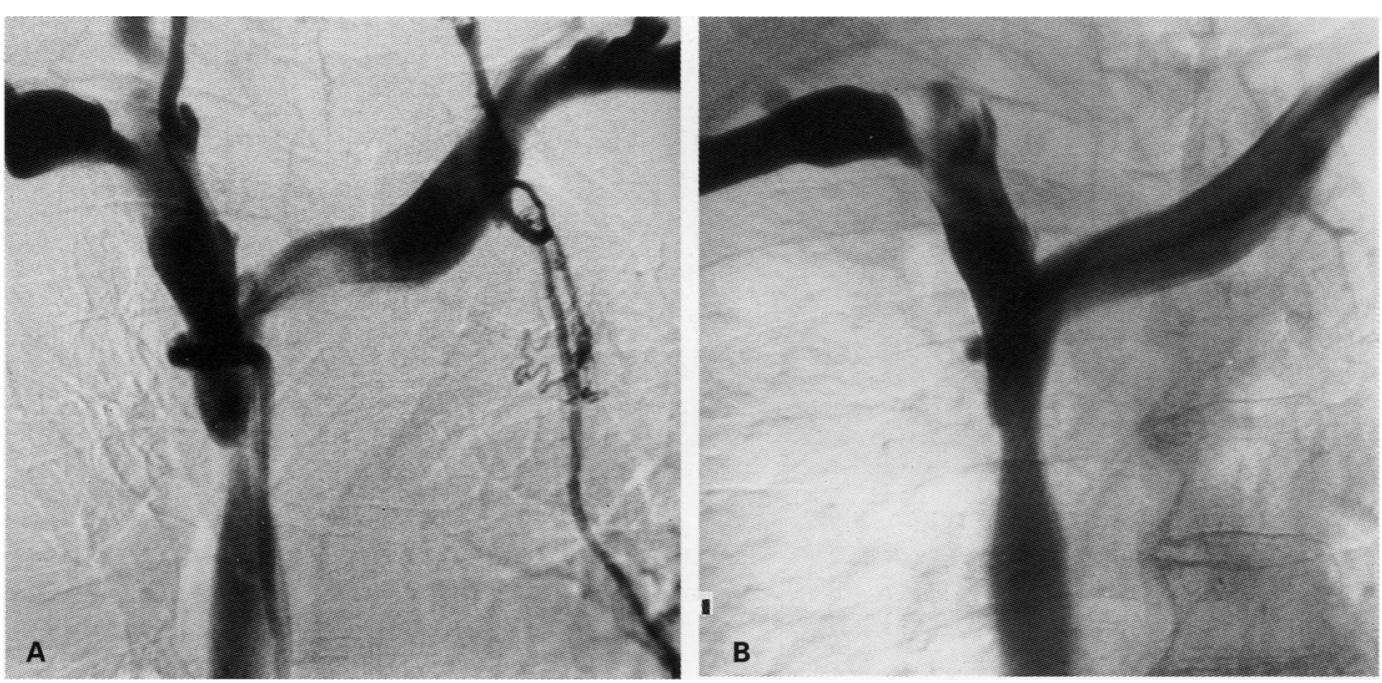

Figure 1 (A) Digital subtraction venogram showing a significant stenosis of the SVC due to tumour compression. (B) Venogram of the same patient after stent implantation and balloon dilatation showing significant improvement of the lumen of the SVC and free flow into the right atrium.

constrained by an outer membrane which can be retracted to release it. At full expansion the stent contracts by up to $70 \%$ of its constrained length, and this has to be considered when positioning it. The shortening of the Wallstent shows no linear relationship to the increase of its lumen. When the stent is almost fully open the shortening becomes more pronounced. The stent is radiopaque and metal markers on the delivery catheter allow exact placement. When not yet fully deployed the stent can be pulled back, but cannot be pushed forwards. Stents of an unconstrained diameter up to $10 \mathrm{~mm}$ can be placed over a 7 French introduction sheath. For larger stents a 9 French sheath is necessary.

\section{STENTING PROCEDURE}

A digital subtraction venogram of the stenosed veins was performed before stenting via a simultaneous injection, usually in a cubital vein, on both sides. After the initial venogram stent placement was planned according to the site and extent of the obstruction. Two patients had large areas of thrombus which was fragmented and lysed before the stenting. This was accomplished by pushing a guidewire through the thrombosis followed by a catheter with side holes which was introduced over it. Urokinase (up to $200000 \mathrm{IU}$ ) was injected through the catheter into the thrombus. Fragmentation of the thrombus was achieved by moving the guidewire and catheter. In addition, a balloon catheter was inflated in the thrombus, compressing it against the vessel wall. A 0.035 inch diameter guidewire (Terumo Corporation, Tokyo, Japan) was then introduced via the antecubital cannula on one or both arms to traverse the stricture or occlusion and was advanced into a large pelvic vein. When this was not possible a right femoral vein approach was used. If the catheter coiled a stiffer guidewire was used. In one patient the right internal jugular vein was used. A sheath (7 or 9 French) was then introduced and the Wallstent endoprosthesis introduced over the guidewire (within the sheath) and positioned across the stricture. When released in a stenosis, the stent normally continues to expand its diameter for a few days. This can be accelerated by balloon dilatation within the stent and was done regularly in our patients. When there was a tight stenosis a balloon dilatation was performed before placement of the stent. The balloon catheter was introduced over the guidewire and placed at the site of stenosis. Dilatation was achieved by inflation of the balloon to a maximum diameter of 8-10 $\mathrm{mm}$. Most procedures produced only slight dilatation. We selected a stent with a fully expanded diameter 1-2 mm larger than the estimated diameter of the vessel segment to be stented. In the SVC we used stents with an unconstrained diameter of 14 or $16 \mathrm{~mm}$. When placed in a $\mathrm{Y}$ configuration in both innominate veins and in the SVC (fig 2) stents with an unconstrained diameter of 10 or $12 \mathrm{~mm}$ were used. When a stent placement into both the right and left innominate veins was necessary, this was performed sequentially from both cubital fossae. The caudal ends of the stents were placed one beside the other in the SVC, and the cranial ends in the right and left innominate veins. In other patients with long stenotic segments two or three overlapping stents were necessary and care was taken that the most caudal stent did not reach the right atrium. When the inflow of an internal jugular vein was to be bridged by a stent, the patency and normal lumen of the contralateral jugular vein was first verified. All the patients were given $5000 \mathrm{IU}$ of heparin intravenously during the procedure. Lifelong anticoagulation therapy was maintained when thrombus was detected at the initial phlebography and in two of three patients after reintervention due to stent thrombosis. A third patient died several hours after reintervention. Anticoagulation varied in the other patients between none and lifelong. Blood pressure, pulse, electrocardiography, and arterial oxygen saturation were monitored in all patients during intervention and in the recovery area. 

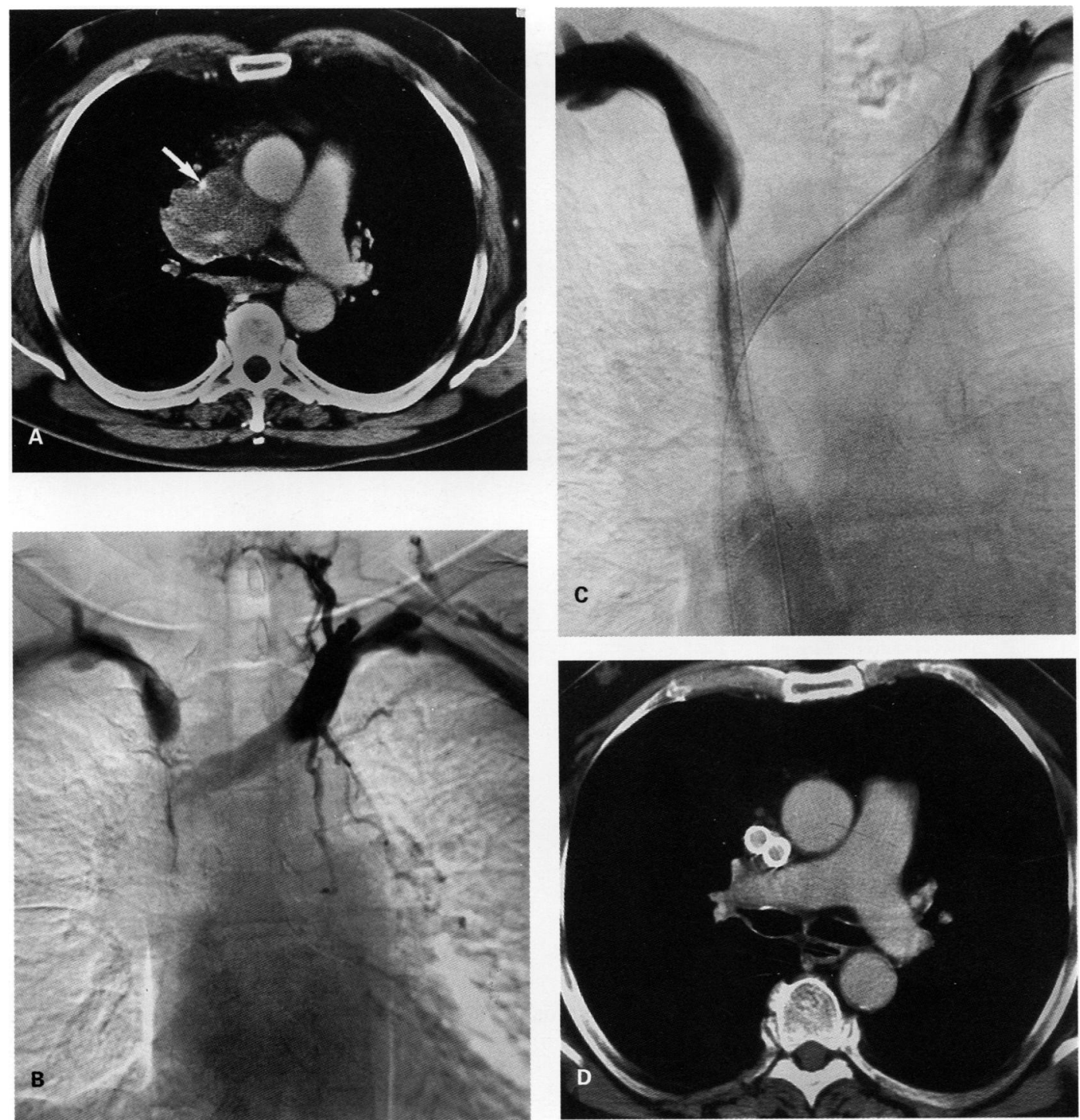

Figure 2 Patient with advanced small cell lung carcinoma. (A) Computed tomographic scan after intravenous injection of contrast medium showing extremely narrowed SVC (arrow). (B) Initial digital subtraction venogram before stent implantation with tightly stenosed SVC. (C) Digital subtraction venogram after release of a second Wallstent showing a good flow in the SVC and the innominate veins. The contrast medium becomes diluted at the inflow of the internal jugular veins. (D) Computed tomographic scan of the lower SVC showing the two Wallstents in the SVC.

\section{Results}

Stent placement was performed in 14 patients without complications. In one, passage of the stenosis of the SVC with the guidewire was feasible via a cubital approach, but the catheter with the Wallstent could not be inserted. The guidewire was advanced further into the right external iliac vein, trapped with an aspiration sheath, and removed via the femoral site with the other end of the guidewire still showing at the cubital site. Bridging of the stenosis with the catheter and the Wallstent could then be achieved over the stabilised guidewire via a femoral introduction sheath without difficulty. Some patients felt chest pain during balloon inflation to increase the stent lumen. The congestive symptoms of obstruction of the SVC improved within two days in 12 patients, sometimes even within hours. Two patients did not benefit from the stents. In one it was not possible to get the catheter across the stenosis from the cubital or femoral veins, so the stent was placed without symptomatic benefit into the azygos vein, a major collateral vein compressed by the tumour. In the other patient an occlusion of the innominate vein could not be recanalised and venous collaterals were insufficient to improve symptoms. Eleven of the 14 patients died between two and 272 days (median 156 days) due to disease progression. The three patients who survived were free of SVC syndrome with a follow up period of 63 , 185 , and 222 days, respectively.

Patency of the stent was assumed while the patient was free of congestive symptoms. The median observation time of the 14 patients was 171 days, during which the median primary patency including initial failures was 83 days (interquartile range 4-169, total range 0-246 days), and the median secondary patency including reinterventions was 124 days (interquartile range 33-210 days, total range 0-272 days). No stents became infected or broken. Patient details, tumour histology, site of obstruction and stent placement, thrombolysis, number of stents, primary symptomatic 
Table 1 Stent placement, primary symptomatic relief and length of follow up

\begin{tabular}{|c|c|c|c|c|c|c|c|}
\hline Patient & $\begin{array}{l}\text { Tumour } \\
\text { histology }\end{array}$ & $\begin{array}{l}\text { Site of } \\
\text { obstruction }\end{array}$ & $\begin{array}{l}\text { Clot fragment- } \\
\text { ation and lysis }\end{array}$ & $\begin{array}{l}\text { No. of } \\
\text { stents }\end{array}$ & $\begin{array}{l}\text { Site of } \\
\text { stent } \\
\text { placement }\end{array}$ & $\begin{array}{l}\text { Duration of primary } \\
\text { symptomatic } \\
\text { relief }\end{array}$ & $\begin{array}{l}\text { Follow up } \\
\text { (days) }\end{array}$ \\
\hline $\begin{array}{r}1 \\
2 \\
3 \\
4 \\
5 \\
6 \\
7 \\
8 \\
9 \\
10 \\
11 \\
12 \\
13 \\
14\end{array}$ & $\begin{array}{l}\text { Thyroid cancer } \\
\text { SCLC } \\
\text { NSCLC } \\
\text { NSCLC } \\
\text { NSCLC } \\
\text { SCLC } \\
\text { NSCLC } \\
\text { NSCLC } \\
\text { SCLC } \\
\text { NSCLC } \\
\text { NSCLC } \\
\text { SCLC } \\
\text { NSCLC } \\
\text { Breast } \\
\text { carcinoma }\end{array}$ & $\begin{array}{l}\text { LAV,LSV,LIV, SVC, RIJV } \\
\text { SVC, Azygos vein, LIV } \\
\text { RIV, LIV, SVC } \\
\text { SVC } \\
\text { SVC } \\
\text { RIV, SVC } \\
\text { SVC } \\
\text { SVC } \\
\text { LAV, LSV, LIV, RIV } \\
\text { LIV, RIV, SVC } \\
\text { LSV, LIV } \\
\text { RIV, LIV } \\
\text { RIV, LIV, SVC } \\
\text { LIV, SVC }\end{array}$ & $\begin{array}{l}\text { Yes } \\
\text { No } \\
\text { No } \\
\text { No } \\
\text { No } \\
\text { No } \\
\text { No } \\
\text { No } \\
\text { No } \\
\text { No } \\
\text { Yes } \\
\text { No } \\
\text { No } \\
\text { No }\end{array}$ & $\begin{array}{l}3 \\
2 \\
3 \\
3 \\
1 \\
3 \\
1 \\
1 \\
2 \\
2 \\
3 \\
2 \\
1 \\
1\end{array}$ & $\begin{array}{l}\text { RIV, RIV, SVC } \\
\text { Azygos vein, SVC, RIV } \\
\text { LIV, SVC } \\
\text { SVC } \\
\text { SVC } \\
\text { LIV, RIV, SVC } \\
\text { SVC } \\
\text { SVC } \\
\text { LIV, RIV, SVC } \\
\text { LIV, RIV, SVC } \\
\text { LSV, LIV, SVC } \\
\text { RIV, LIV, SVC } \\
\text { RIV, SVC } \\
\text { SVC }\end{array}$ & $\begin{array}{r}0 \\
0 \\
2 \\
246 \\
77 \\
222 \\
86 \\
95 \\
204 \\
80 \\
6 \\
185 \\
152 \\
63\end{array}$ & $\begin{array}{l}10 \text { (died) } \\
210 \text { (died) } \\
2 \text { (died) } \\
247 \text { (died) } \\
215 \text { (died) } \\
222 \text { (died) } \\
86 \text { (died) } \\
95 \text { (died) } \\
204 \text { (died) } \\
80 \text { (died) } \\
272 \text { (died) } \\
185 \text { (died) } \\
156 \text { (died) } \\
63\end{array}$ \\
\hline
\end{tabular}

SCLC = small cell lung cancer; NSCLC = non-small cell lung cancer; LAV = left axillary vein; LSV = left subclavian vein; LIV = left innominate vein; $S V C=$ superior vena cava; RIV = right internal jugular vein; RIV = right innominate vein.

Table 2 Tumour therapy and reinterventions

\begin{tabular}{|c|c|c|c|c|c|c|c|}
\hline Patient & $\begin{array}{l}\text { Tumour } \\
\text { histology }\end{array}$ & $\begin{array}{l}\text { Tumour therapy } \\
\text { before stenting }\end{array}$ & $\begin{array}{l}\text { Tumour } \\
\text { therapy after } \\
\text { stenting }\end{array}$ & $\begin{array}{l}\text { Duration of } \\
\text { anticoagulation } \\
\text { (days after first } \\
\text { stenting) }\end{array}$ & $\begin{array}{l}\text { Reintervention due to stent } \\
\text { thrombosis (days after first } \\
\text { stenting) }\end{array}$ & $\begin{array}{l}\text { Symptomatic relief } \\
\text { after neintervention } \\
\text { (days) }\end{array}$ & Comments \\
\hline 1 & Thyroid cancer & Surgery & & 10 & - & - & $\begin{array}{l}\text { Tracheal stent } \\
\text { implantation } \\
\text { before and after } \\
\text { venous stenting }\end{array}$ \\
\hline 2 & SCLC & Chemotherapy & Chemotherapy & 61 & - & - & \\
\hline 4 & NSCLC & Chemotherapy & Radiotherapy & 90 & 247 & 0 & $\begin{array}{l}\text { Laser therapy and } \\
\text { stent placement in } \\
\text { the right main } \\
\text { bronchus one day } \\
\text { before stent } \\
\text { thrombosis }\end{array}$ \\
\hline 5 & NSCLC & $\begin{array}{l}\text { Chemotherapy } \\
\text { Radiotherapy }\end{array}$ & $\begin{array}{l}\text { Radiotherapy } \\
\text { Chemotherapy } \\
\text { Endoluminal } \\
\text { brachytherapy } \\
\text { (106 days after } \\
\text { first stenting) }\end{array}$ & - & 78 & 137 & $\begin{array}{l}\text { Balloon dilation } \\
\text { and stent } \\
\text { implantation in the } \\
\text { right main } \\
\text { bronchus one day } \\
\text { before stent } \\
\text { thrombosis }\end{array}$ \\
\hline 6 & SCLC & Chemotherapy & Chemotherapy & 222 & - & - & \\
\hline 7 & NSCLC & - & Radiotherapy & & 7 & - & - \\
\hline 8 & NSCLC & $\begin{array}{l}\text { Radiotherapy } \\
\text { Endoluminal } \\
\text { brachytherapy } \\
\text { (11 days before) }\end{array}$ & $\begin{array}{l}\text { Endoluminal } \\
\text { brachytherapy } \\
\text { ( } 2 \text { days after } \\
\text { venous } \\
\text { stenting) }\end{array}$ & - & - & - & $\begin{array}{l}\text { Balloon dilation } \\
\text { and stenting of the } \\
\text { right main } \\
\text { bronchus } 35 \text { days } \\
\text { before venous } \\
\text { stenting }\end{array}$ \\
\hline 9 & SCLC & Chemotherapy & $\begin{array}{l}\text { Chemotherapy } \\
\text { Radiotherapy }\end{array}$ & - & - & - & $\begin{array}{l}\text { Tracheabronchial } \\
\text { Y stent } 170 \text { days } \\
\text { after venous } \\
\text { stenting }\end{array}$ \\
\hline 10 & NSCLC & Surgery & Radiotherapy & 80 & $\overline{7}$ & - & \\
\hline 11 & NSCLC & - & Radiotherapy & 5 & 7 & 265 & $\begin{array}{l}\text { Laser therapy and } \\
\text { stent implantation } \\
\text { in the left main } \\
\text { bronchus one day } \\
\text { before stent } \\
\text { thrombosis }\end{array}$ \\
\hline 12 & SCLC & $\begin{array}{l}\text { Chemotherapy } \\
\text { Radiotherapy } \\
\text { (bone) }\end{array}$ & Chemotherapy & - & - & - & \\
\hline 13 & NSCLC & Chemotherapy & Chemotherapy & 40 & - & - & \\
\hline 14 & Breast cancer & Chemotherapy & Chemotherapy & - & - & - & \\
\hline
\end{tabular}

SCLC $=$ small cell lung cancer; NSCLC $=$ non-small cell lung cancer.

relief, and follow up are summarised in table 1.

Table 2 gives further information about tumour therapy before and after venous stenting, the duration of anticoagulation immediately after venous stenting, and reinterventions.

\section{REINTERVENTIONS}

A reintervention resulting from stent thrombosis was necessary in three patients after seven, 78 , and 247 days. All three developed thrombosis one day after general anaesthesia for stent placement in the right or left main bronchus. Two patients received laser therapy for endo- bronchial tumour at the same time. None of the three patients was anticoagulated at this time. Two further patients who had endobronchial stents after venous stenting were not anticoagulated and had no thromboses. Patency of the venous lumen was achieved at reintervention in all three patients by thrombus fragmentation and local thrombolysis with urokinase up to one million units. In two patients a further vascular stent was introduced.

\section{Discussion}

Stent placement in the vena cava and large veins of patients with cancer has already been 

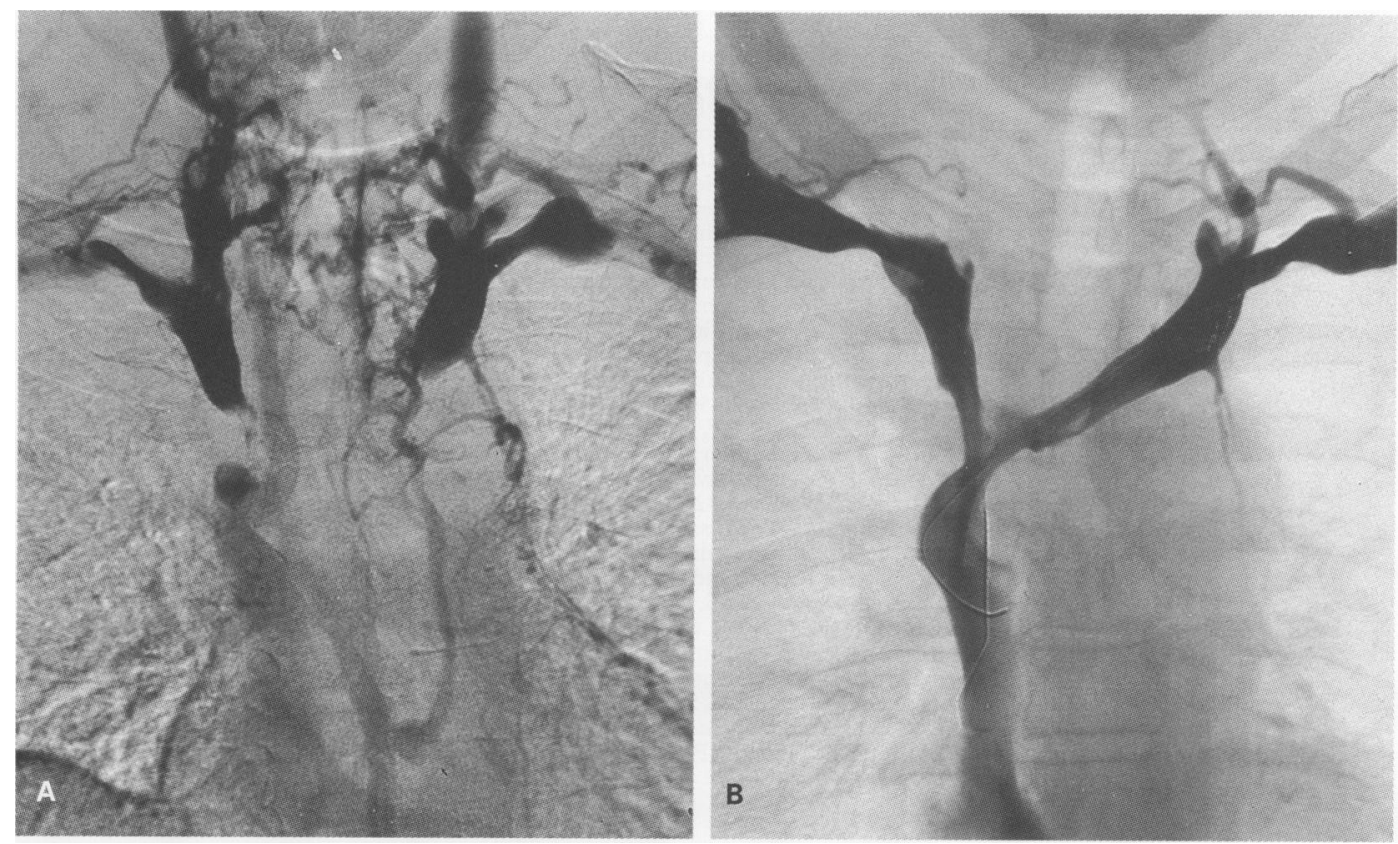

Figure 3 (A) Venogram showing obstruction of the SVC and the confluence of the innominate veins with extensive collaterals. (B) After stenting with two Wallstents in a Y configuration there is good flow in the SVC and the collateral veins are no longer opacified.

reported to be an effective treatment for venous stenosis and the resulting congestive symptoms. ${ }^{59120}$ Symptomatic relief occurs within hours to days and produces a significant improvement in quality of life. Whether stent placement in patients with advanced incurable malignancies should now be considered as the best initial treatment for obstruction of the SVC is debatable. The traditional treatment for these patients has been radiation therapy. In comparison with the results of treatment with venous stents, patients with radiation and/ or chemotherapy show a delay in symptomatic relief and some patients do not respond at all.

Major causes of restenosis and occlusion after stent placement are thrombosis, intimal thickening, and further tumour growth. Three patients developed stent thrombosis one day after endobronchial treatment under general anaesthesia. It is unclear whether this was a coincidence or if there is a pathophysiological relationship. We suggest that when both stenting of the SVC and the tracheobronchial tree is necessary, the possibility of a higher risk of thrombosis after endobronchial stenting and anaesthesia should be taken into consideration.

Full heparinisation is mandatory during stenting. Different practices for anticoagulant treatment following stent placement have been described. Some authors favour lifelong anticoagulation $^{5}$ while others prescribe anticoagulation therapy for several months ${ }^{1417}$ or not at all. ${ }^{89}$ The benefits of an anticoagulation need, as usual, to be weighed against the risk of bleeding complications. So far there have been no controlled clinical trials. We now anticoagulate (if no contraindications are present) for three months and consider that permanent anticoagulation is sensible after thrombosis.

The use of several Wallstents for overlapping stenting to cover larger vessel segments is well established. In three patients we used a technique with one stent in each innominate vein, lying one beside the other with their lower ends in the SVC and with each of their cranial tips in the two innominate veins (fig 3). ${ }^{17}$ This technique provides good protection to the confluence of the innominate veins against tumour stenosis. In one patient it was necessary to place a stent through the dilated mesh of the first stent during a second intervention because of stenosis and thrombosis. Placement was technically successful but a stenosis remained where the second stent passed through the mesh of the first. The patient received anticoagulation therapy and remained free of congestive symptoms. This configuration of stent placement was unusual. Stent migration, perforation, or stent infection, which can be fatal, ${ }^{21}$ did not occur. Other possible complications include a false aneurysm at the site of the stenosis due to excessive dilatation, an arteriovenous fistula at the puncture site, and bleeding during anticoagulation. The location of a stent should be known before placement of a central venous catheter to avoid stent deformation, thrombosis, and injury.

It is reasonable to perform a stent placement before venous occlusion and thrombosis has occurred. We consider that the indications for stent placement include the onset of congestive symptoms, significant stenosis in the initial venogram, and cases where the underlying disease is not curable. With this procedure immediate relief is achieved and only a short hospital stay is necessary.

1 Perez CA, Presant CA, Van Amburg AL. Management of superior vena cava syndrome. Semin Oncol 1978;5:123-34. 2 Chen JC, Bongard F, Klein SR. A contemporary perspective on superior vena cava syndrome. Am F Surg 1990;160: 207-11.

3 Beck C, Berberich W, Bauknecht A, Schnabel K. Die obere Einflussstauung als Notfall in der Strahlentherapie. Strah lenther Onkol 1990;166:798-802.

4 Charnsangavej $\mathrm{C}$, Carrasco $\mathrm{CH}$, Wallace $\mathrm{S}$, Wright $\mathrm{KC}$, Ogawa K, Richli W, et al. Stenosis of the vena cava: preliminary assessment of treatment with expandable metallic stents. Radiology 1986;161:295-98. 
5 Rösch J, Uchida BT, Hall LD, Antonovic R, Petersen BD, Ivancev $\mathrm{K}$, et al. Gianturco-Rösch expandable $\mathrm{Z}$-stents in the treatment of superior vena cava syndrome. Cardiovasc Intervent Radiol 1992;15:319-27.

6 Putnam JS, Uchida BT, Antonovic R, Rösch J. Superior vena cava syndrome associated with massive thrombosis: vena cava syndrome associated with massive stents. Radiology 1988 ; treatment

7 Rösch J, Bedell JE, Putnam J, Antonovic R, Uchida B. Gianturco expandable wire stents in the treatment of superior vena cava syndrome recurring after maximumtolerance radiation. Cancer 1987;60:1243-6.

8 Edwards RD, Cassidy J, Taylor A. Case report: superior vena cava obstruction complicated by entral venous thrombosis - treatment with thrombolysis and Gianturco-Z stents. Clin Radiol 1992;45:278-80.

9 Irving JD, Dondelinger RF, Reidy JF, Schild H, Dick R, Adam A, et al. Gianturco self-expanding stents: clinical Adam A, et al. Gianturco self-expanding stents: clinical
experiene in the vena cava and large veins. Cardiovasc experiene in the vena cava and
Intervent Radiol 1992;15:328-33.

10 Kishi K, Sonomura T, Mitsuzane K, Nishida N, Yang R, Sato $M$, et al. Self-expandable metallic stent therapy for superior vena cava syndrome: clinical observations. Radiology 1993;189:531-5.

11 Edwards RD, Jackson JE. Case report: superior vena caval obstruction treated by thrombolysis, mechanical thrombectomy and metallic stents. Clin Radiol 1993;48:215-7.

12 Oudkerk M. Heystraten FM, Stoter G. Stenting in malignant vena caval obstruction. Cancer 1993;71:142-6.

13 Dondelinger RF, Goffette P, Kurdziel JC, Roche A. Ex- pandable metal stents for stenoses of the venae cavae and large veins. Semin Intervent Radiol 1991;8:252-63.

14 Zollikofer CL, Antonucci F, Stuckmann G, Mattias P, Brühlmann WF, Salomonowitz EK. Use of the Wallstent in the venous system including hemodialysis-related stenoses. Cardiovasc Intervent Radiol 1992;15:334-41.

15 Antonucci F, Salomonowitz E, Stuckmann G, Stiefel M, Largiadèr J, Zollikofer CL. Placement of venous stents: clinical experience with a self-expanding prosthesis. clinical experience with
Radiology 1992;183:493-7.

16 Watkinson AF, Hansell DM. Expandable Wallstent for the treatment of obstruction of the superior vena cava. Thorax 1993;48:915-20.

17 Dyet JF, Nicholson AA, Cook AM. The use of the Wallsten endovascular prosthesis in the treatment of malignan obstruction of the superior vena cava. Clin Radiol 1993; 48:381-5.

18 Vanhoenacker P, Crolla D, De Muynck P. Venous stenting with a self-expanding prosthesis in superior vena cava syndrome. Fortschr Röntgenstr 1994;160:178-80.

19 Elson JD, Becker GJ, Wholey MH, Ehrmann KO. Vena caval and central venous stenoses: management with Palmaz and central venous stenoses: management with Palmaz
balloon-expandable intraluminal stents. $\mathcal{F}$ Vasc Intervent Radiol 1991;2:215-23.

20 Solomon N, Wholey MH, Jarmolowski CR. Intravascula stents in the management of superior vena cava syndrome. Cathet Cardiovasc Diagn 1991;23:245-52.

21 Therasse E, Soulez G, Cartier P, Passerini L, Roy P, Bruneau $\mathrm{L}$, et al. Infection with fatal outcome after endovascula metallic stent placement. Radiology 1994;192:363-5. 